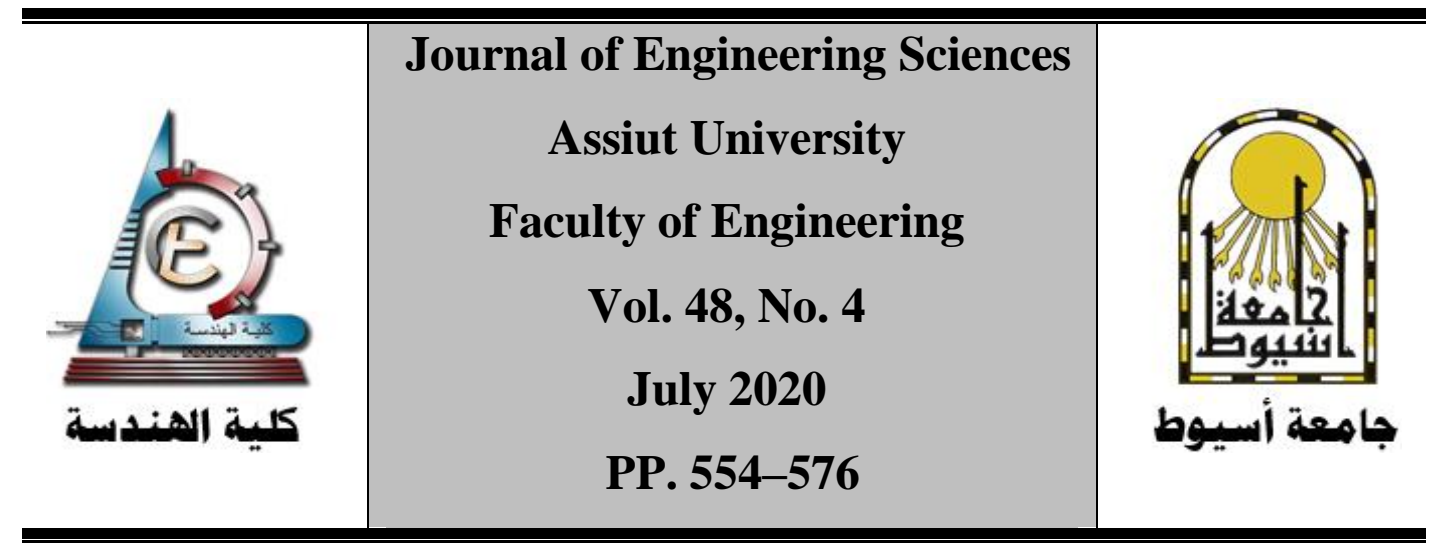

\title{
NONLINEAR FINITE-ELEMENT ANALYSIS FOR RC BEAMS STRENGTHENED WITH FABRIC-REINFORCED CEMENTITIOUS MATRIX
}

Mohamed Nagah', Ahmed Arafa ${ }^{2}$, Ahmed Attia M. Drar ${ }^{3}$ and Yehia. A. Hassanean ${ }^{4}$

${ }^{1}$ Demonstrator, Civil Department, Faculty of Engineering, Sohag University, Egypt.E-mail: mahamed.noureldin@yahoo.com

${ }^{2}$ Lecturer, Civil Department, Faculty of Engineering, Sohag University, Egypt.

E-mail: ahmed_arafa@eng.sohag.edu.eg (Corresponding Author)

${ }^{3}$ Assist. Prof., Civil Engineering Department, Faculty of Engineering, Sohag

University, Egypt.E-mail: attya85@yahoo.com

${ }^{4}$ Professor, Civil Department, Faculty of Engineering, Assiut University, Egypt.

E-mail: yehiamk@yahoo.com

Received 15 June 2020; Revised 26 July 2020; Accepted 4August 2020

\begin{abstract}
Because of the shortcomings of the externally bonded system that mainly consists of epoxy and FRP sheets, the fabric-reinforced cementitious matrix, (FRCM) represents a viable solution in the strengthening of reinforced concrete beams. The FRCM layers consist of fabric mesh embedded in an inorganic stabilized cementitious mortar. Many experimental studies examined the impact of strengthening of RC beams with the FRCM layers, but the numerical investigations are limited. This study is therefore aimed at introducing a numerical study investigating the behavior of RC beams reinforced with FRCM layer. The main goal of this paper is to verify the FEM results with the experimental results that are available in the previous study [1], and to provide a parametric study. The investigated beams in this paper are $150 \mathrm{~mm} \times 250 \mathrm{~mm} \times 3000 \mathrm{~mm}$ with two reinforcement ratios. One, two, and three-layers of PBO, (P-Phenylene Benzobis Oxazole) FRCM were investigated as strengthening of the simulated beams were strengthened with. The numerical validation included load-deflection curve, load strain of both concrete and PBO- FRCM, strain distribution, cracks series and failure
\end{abstract}


mode. The built model gave an accurately prediction of the attitude of the investigated beams. The results also indicated that the rise in the reinforcement ratio or the amount of FRCM layers contributed to improving behavior under both ultimate and serviceability limit states.

KEYWORDS: Externally bonded system (FRP), Fabric-reinforced cementitious matrix (FRCM), FEM

\section{Introduction}

The reinforcement of RC beams by using external fiber reinforced polymer ( FRP) composites has been studied in several previous works [12]. The reason is that the FRP have good mechanical characteristics such as maximum tensile strength, elastic modulus, and high strength-to-weight ratio and resists the corrosion. Moreover, the external (FRP) bond consists of fibres or laminates connected to the bottom surface of the reinforc ed beam using adhesive material called epoxy to enhance its structural behavi or at both serviceability and ultimate conditions. Although using of epoxy to bond the fabrics and the concrete have several advantages like being an excellent glue material and it is good in transferring the load to fabric, many disadvantages exist such as low resistance to the fire and high temperature [13-14], low resistance to ultraviolet radiation (UR), lack of permeability and diffusion tightness [2]. The disadvantages lead to strength degradation and affect the external (FRP) bond to strength the defective beams. So, to reduce some of these drawbacks the fiber-reinforced cementitious matrix (FRCM) has been used rather than the external (FRP). The (FRCM) consists of cementitious mortar and fiber mesh or grid. The fiber mesh is embedded in the mortar of cement which is used as a glue material to bond the fiber mesh with the soffit of the concrete beam, see Figure (1).

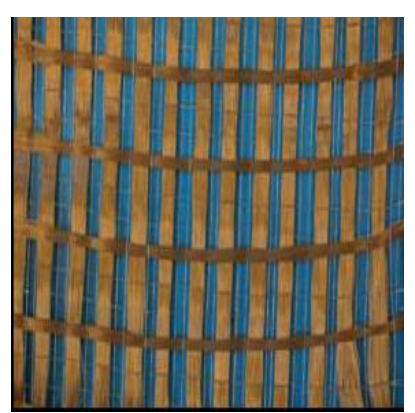

(a)

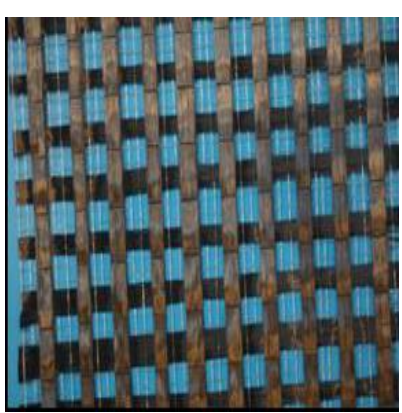

(b)

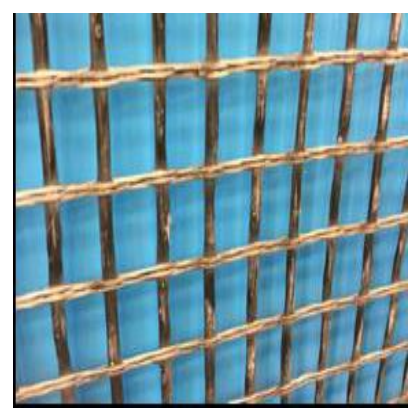

(c)

Figure (1) - Types of fiber mesh: (a) PBO; (b) carbon; (c) glass. [2] 
Recently, experimental and few theoretical studies were carried out to examine the strengthening of RC beams with (FRCM). Experimental and theoretical flexural analysis of RC beams strengthened with a cement based high strength composite material was studied by Luciano Ombres, [1]. The parameters studied in this paper were the longitudinal reinforcement ratio $(A s / A c)$ and the layers number of PBO-FRCM. The results indicated that the usage of (PBO-FRCM) layers lead to an improvement in the yielding and ultimate strength of the examined RC beams and it generally improves the flexural ability of the examined beams. On the other hand, the ductility of the investigated beams decreases when increasing the major reinforcement ratio and the amount of (FRCM) layers. It was also reported that the failure was flexural crushing of concrete when one layer was used while layers delamination was dominant when extra layers were used. Also, an experimental and theoretical analysis of the effect of the fiber type and axial stiffness of FRCM on the flexural strengthening of RC beams was investigated by Abdulla Jabr, et al, [2]. The studied parameters were the longitudinal reinforcement ratio and the used fiber type (glass, carbon and PBO fibers). The results revealed that the using of PBO - FRCM achieved an excellent impact on increasing the ultimate strength of investigated beams. On the other side, the carbon and glass FRCM system did not achieve a tangible increase in the ultimate strength of the examined beams. Moreover, it was observed that when the axial stiffness ratios (EAFRCM/EAsteel) decrease the increasing in ultimate load decrease also. Furthermore, experimental investigation of the effect of corrosion damage on the flexural performance of RC beams strengthened with FRCM composites was studied by Mohammed Elghazy, et al, [3]. The kind of FRCM (PBO and Carbon FRCM), the layers number of FRCM (two, three, and four), and the shape of FRCM system (end-anchored and continuously wrapped) were investigated in this paper. The results indicated that the corrosion of the steel bar caused decreasing the yielding and ultimate strength by 15 and $9 \%$, respectively. The flexural strength of the corrosion damaged beams was enhanced due to use of the PBO and carbon -FRCM layer. The failure mode and the ultimate strength of the investigated beam depend on the type, number, and the shape of FRCM layer. Finally, an experimental study of the effect of a novel and effective anchorage system for enhancing the flexural capacity of RC beams strengthened with FRCM composites was investigated by Zena R. Aljazaeri, et al, [4]. They investigated the effect of two anchorage systems on the failure of FRCM layer, the two anchorages were a glass spike anchor and a novel U-wrapped anchor. Results indicated that the beams were strengthened with two layers of PBO - FRCM which were anchored, and the nonanchored system did not affect the ultimate strength. On the other hand, it had a great effect on the failure mode where the failure changes due to use 
Mohamed Nagah et al., Nonlinear Finite-Element Analysis for Rc Beams Strengthened......

the anchored system from a debonding failure to a slippage failure of the PBO sheets. Using the two anchorage systems increased the ultimate load by $24 \%$ compared with beams without anchorage system. Moreover, using of the anchored U-wrapped PBO strip resulted in ultimate load gain and improving the serviceability of examined beams with respect to the glass spike anchored system.

Most of the mentioned researches present only experimental studies. So, this paper introduces a numerical method to analyze the enhancement of RC beams with FRCM and verifying the results obtained from the FEM with the previous experimental studies [1]. Moreover, this study presents a proposed method to numerically evaluate the enhancement of reinforcement concrete beams with FRCM. As well as presents the failure mechanics of RC beams strengthened with FRCM.

\section{3- Methodology}

Full scale RC beams strengthened with PBO-FRCM layer subjected to two concentrated static loads were studied by using commercial FE software "ABAQUS" [5]. Furthermore, 3D finite elements were used to model the whole element. The considered material and geometric model in addition to modeling the bond behavior between the FRCM layer and the soffit of the concrete beam are shown in Figure (2).

\subsection{Numerical Model}

For the proposed finite element model, both the concrete parts and cementitious mortar were modeled as eight-node linear brick elements (C3D8R) [5]. Moreover, two-node linear 3D truss element (T3D2) was suitable to model the longitudinal and transverse reinforcement [5]. Finally, the fabric mesh was modeled as a 4-node doubly curved thin or thick shell (S4R) [5]. Many different mesh sizes were used and gave the same results. So, to decrease the run process time, a uniform mesh was used in the developed model, its dimension is $(25 \times 25) \mathrm{mm}$. Figure (2) shows the details of the FEM mesh.

\subsection{Concrete Model}

The concrete damaged plasticity (CDP) model was established in ABAQUS for concrete elements [6], which is available for modeling of RC elements subjected to static, cyclic, monotonic, and dynamic loads. CDP is available to express both the elastic and the plastic behavior of the concrete in compression. The parameters of CDP are listed in Table (1). The stress-strain 
curve of concrete was modeled according to Carreira and Chu model [7]. This model is widely used to express the stress-strain relationship of the concrete. The concrete behavior was expected to be an elastic linear till reaching $0.4 f \mathrm{c}^{\prime}$, after this stage, the plastic behavior occurs according to equation No. (1).
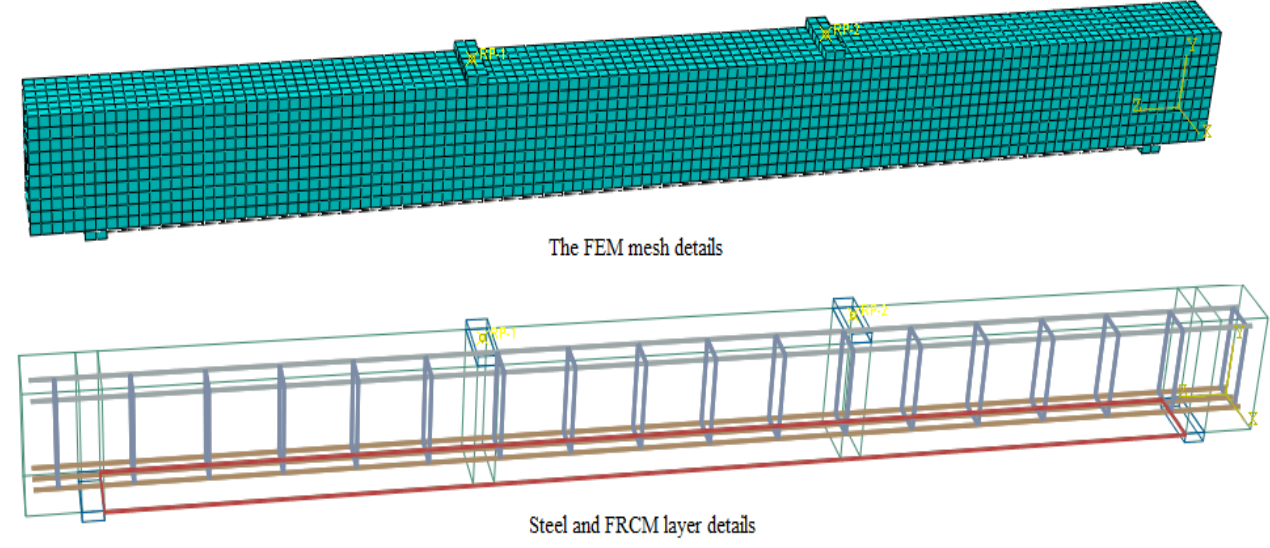

Figure (2) - Typical 3D-FEM details for the simulated beams strengthened with PBO FRCM layers

$$
f_{c}=f_{c}^{\prime} \times \frac{\beta\left(\varepsilon / \varepsilon c^{\prime}\right)}{\beta-1+\left(\varepsilon / \varepsilon c^{\prime}\right)^{\beta}}
$$

Where $f \mathrm{c}$ is the uniaxial compressive stress, $f c^{\prime}$ is the characteristic uniaxial compressive strength of concrete, $\varepsilon_{c}^{\prime}$ is the concrete strain corresponding to $f c^{\prime}$ and $\beta$ is a material parameter that depends on the shape of the stress-strain curve and can be estimated using Eq. (2\&3), and $\varepsilon$ is the uniaxial compressive strain.

$$
\begin{gathered}
\beta=\left(f_{c}^{\prime} / 32.4\right)^{3}+1.55, \\
\varepsilon_{c}^{\prime}=0.002,
\end{gathered}
$$

For concrete tension behavior according to Carreira and Chu model, it displays a linear increase until reaching the point of the maximum tensile strength $f_{t}^{\prime}$ and a linear decrease until reaching zero. The stress-strain curve for the concrete in tension and compression is shown in Figure (3). The maximum uniaxial tensile strength can be estimated from the following equation

$f_{t}^{\prime}=0.1 \times f_{c}^{\prime}$ 
Mohamed Nagah et al., Nonlinear Finite-Element Analysis for Rc Beams Strengthened......

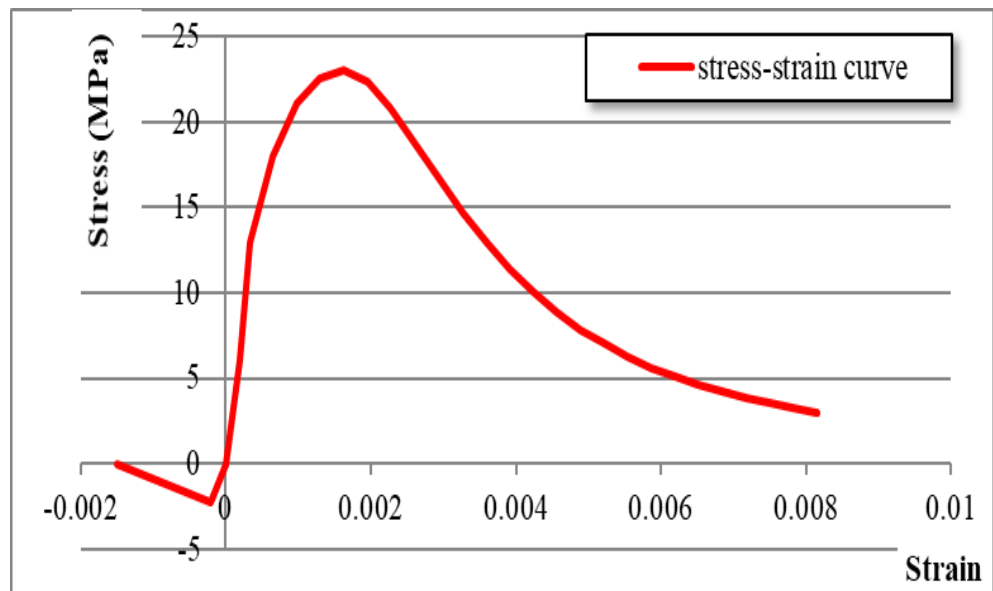

Figure (3) - Stress-strain curve for the concrete in tension and compression

Table (1) parameters of the concrete damage plasticity model for concrete [6]

\begin{tabular}{|l|c|}
\hline Parameter & Value \\
\hline Compressive strength of concrete, $f_{c^{\prime}}(\mathrm{MPa})$ & $f_{c^{\prime}}$ \\
\hline Tensile strength of concrete, $f_{t^{\prime}}(\mathrm{MPa})$ & $0.1 f_{c^{\prime}}$ \\
\hline Poisson's ratio, $v$ & 0.15 \\
\hline Compressive damage variable, $d_{c}$ & $1-\left(\sigma_{c} / f_{c^{\prime}}\right)$ \\
\hline Tensile damage variable, $d_{t}$ & $1-\left(\sigma_{t} / f_{t^{\prime}}\right)$ \\
\hline Dilation angle, & 35 \\
\hline Eccentricity, $\varepsilon$ & 0.1 \\
\hline $\begin{array}{l}\text { The ratio of initial equibiaxial compressive yield stress to initial uniaxial } \\
\text { compressive yield stress, }\left(f_{b o} / f_{c o}\right)\end{array}$ & 1.16 \\
\hline Ratio of stress invariants, $\mathrm{K}$ & 0.667 \\
\hline Viscosity Parameter, $\mu$ & 0 \\
\hline
\end{tabular}

\subsection{Steel Model}

The steel was modeled as elastic - perfectly plastic material as shown in Figure (4), which increases linearly from zero till reaching to the yielding strength of the steel bars (longitudinal and stirrups bars). The characteristics of steel in all investigated beams [1] are listed in Table (2). In the finite element model, the elasticity modulus, and the poison's ratio of the steel are defined. The elastic modulus and poison's ratio were assumed as (200 GPa) and (0.3), respectively. 
Table (2) Properties of concrete and steel used in investigated beams

\begin{tabular}{|l|l|l|l|l|l|}
\hline Beam No. & $f c^{\prime}\left(\mathrm{N} / \mathrm{mm}^{2}\right)$ & $f t^{\prime}\left(\mathrm{N} / \mathrm{mm}^{2}\right)$ & $\mathrm{E}_{\mathrm{c}}\left(\mathrm{N} / \mathrm{mm}^{2}\right)$ & $\begin{array}{l}\text { Rebar } \\
\text { diameter }\end{array}$ & $f_{\mathrm{y}}\left(\mathrm{N} / \mathrm{mm}^{2}\right)$ \\
\hline $\mathrm{S} 1$ & 23 & 2.3 & 28160 & 10 & 525.90 \\
\cline { 5 - 6 } & 23 & 2.3 & 28160 & 12 & 535.60 \\
\cline { 5 - 6 } & 23 & 2.3 & 10 & 515.44 \\
\hline
\end{tabular}

Note: $f_{t}^{\prime}=$ Concrete tensile strength; $E_{c}=$ Elastic modulus of concrete in compression and $f_{y}$ $=$ Steel yield strength

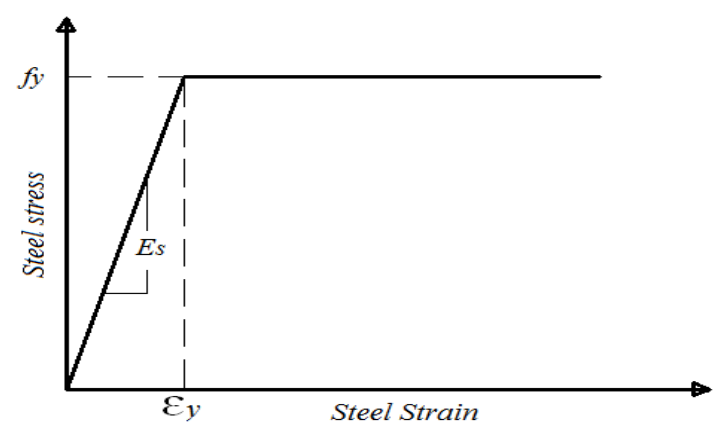

Figure (4) - Stress - strain relationship for steel

\subsection{Fabric Mesh Model}

PBO- fabric mesh sheet was defined as a 4-node doubly curved thin or thick shell (S4R) in the FEM [5]. The stress-strain curve of the fabric mesh is assumed as a linear-elastic material with brittle failure when reaching the maximum tensile strength, as shown in Figure (5). The properties of the PBO-FRCM layer are shown in Table (3)

\subsection{Cementitious Mortar Model}

The cementitious mortar was modeled using eight-node linear brick element, C3D8R, [5]. The cementitious mortar is defined as high strength concrete, which considers the same stress-strain curve of the concrete as shown in Figure (3), and its mechanical characteristics are listed in Table (3).

\subsection{Bond-Slip Model}

The bond behavior between the FRCM layer and the concrete was experimentally studied in many previous papers [8-11]. Which stated on the structural effects of these interventions strongly depends on the bond between the strengthening material and the concrete. The bond behavior was defined as cohesive interaction between concrete and FRCM layer, which was modeled according to the following equation [8] and as shown in Figure (6). The maximum Traction $\left(N_{\max }\right)$ was assumed as (3 $\left.\mathrm{MPa}\right)$, while the 
Mohamed Nagah et al., Nonlinear Finite-Element Analysis for Rc Beams Strengthened......

displacement at damage initiation $\left(\delta_{n}^{\text {intial }}\right)$ and the displacement at damage failure $\left(\delta_{n}^{\text {fail }}\right)$ were assumed as $(0.051 \mathrm{~mm})$ and $(2.5 \mathrm{~mm})$, respectively as proposed by Luciano Ombres, [9].

$$
\begin{gathered}
K_{n n}=\frac{N_{\max }}{\delta_{n}^{\text {intial }}} \\
K_{n n(s o f)}=\frac{N_{\max }}{\delta_{n}^{\text {fail }}-\delta_{n}^{\text {intial }}}
\end{gathered}
$$

Where $\mathrm{K}_{\mathrm{nn}}, \mathrm{K}_{\mathrm{ss}}, \mathrm{K}_{\mathrm{tt}}$ is the stiffness of the cohesive element in normal and $K_{n n(s o f)}$ is the softening of cohesive element in normal and $N_{\max }$ is the maximum Traction and $\delta_{n}^{\text {intial }}$ is the displacement at damage initiation.

Table (3): Properties of PBO-fabric mesh and cementitious mortar used in investigated beams [1]

\begin{tabular}{|l|l|l|l|l|l|}
\hline property & $\begin{array}{l}\text { Nominal } \\
\text { thickness }(\mathrm{mm})\end{array}$ & $\begin{array}{l}\text { Elastic } \\
\text { modulus } \\
(\mathrm{GPa})\end{array}$ & $\begin{array}{l}\text { Tensile } \\
\text { strength } \\
(\mathrm{MPa})\end{array}$ & $\begin{array}{l}\text { Tensile } \\
\text { strain } \\
(\%)\end{array}$ & $\begin{array}{l}\text { Compression } \\
\text { strength } \\
(\mathrm{MPa})\end{array}$ \\
\hline $\begin{array}{l}\text { PBO fiber } \\
\text { mesh }\end{array}$ & $\begin{array}{l}0.0455 \\
(\text { longitudinal }) \\
0.0224 \\
\text { transversal })\end{array}$ & 270 & 5800 & 2.15 & - \\
\hline Mortar & 3 & 6 & 3.50 & - & 29 \\
\hline
\end{tabular}

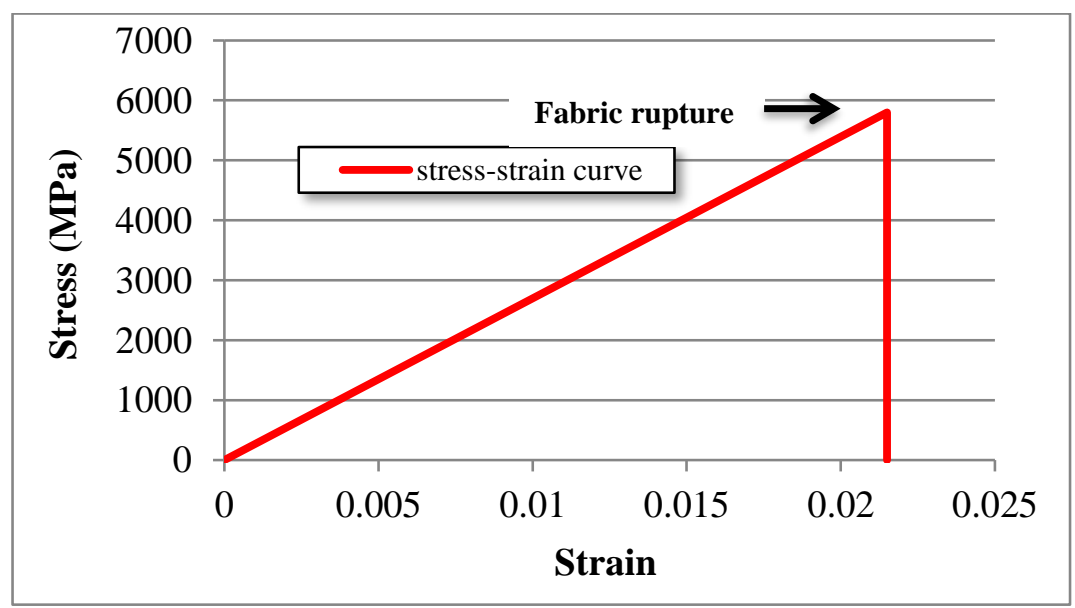

Figure (5) - Stress-strain relationship for the PBO- Fabric mesh sheet 


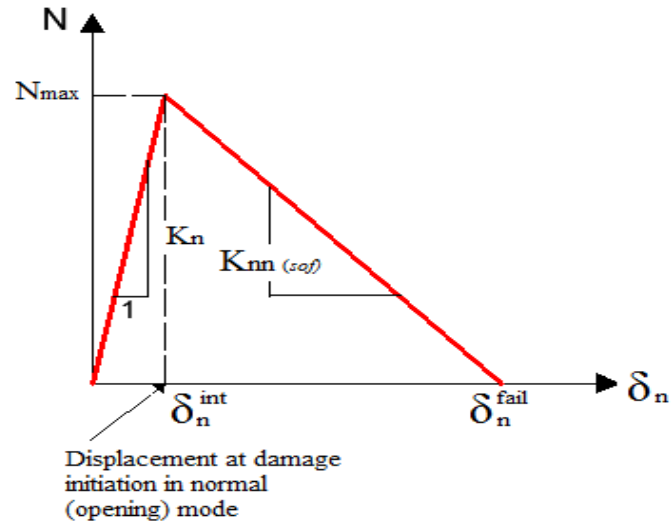

Figure (6) Traction-separation curve for Mode I (Opening Mode)

\section{Details of Analyzed Beams}

The investigated beams in this paper are simply supported with two hinged supports resulting in a total span $3000 \mathrm{~mm}$ with, $2700 \mathrm{~mm}$ clear span and 150 $\mathrm{mm} \times 250 \mathrm{~mm}$ Cross-section as shown in Figure (7). A total of six beams were investigated and classified into two groups, S1and S2. Group S1 contains beams reinforced with two bars $10 \mathrm{~mm}$ diameter as the bottom longitudinal reinforcement with a reinforcement ratio of $0.4 \%$ and two bars 8 diameter as stirrup hanger. Group S2 contains beams reinforced with three bars $12 \mathrm{~mm}$ diameter as bottom longitudinal reinforcement with a reinforcement ratio of $0.9 \%$ and two bars 10 diameter as stirrup hanger. Moreover, all beams used one stirrup $8 \mathrm{~mm}$ each $170 \mathrm{~mm}$ as shear reinforcement to prevent the failure due to shear, and all beams have $20 \mathrm{~mm}$ concrete cover, as shown in Figure (7). These beams were reinforced with PBO-FRCM layers to enhance its flexural strength, the characteristics of each beam are shown in Table (4). Each beam in this study equivalent to a corresponding beam in the experimental study of Luciano Ombres, [1], see Table (5). Two vertical concentrated loads were applied at the top loading plates of the rigid steel plate. Similarly, two rigid plates were simulated to represent the supporting points at which the points restrained in $\mathrm{x}$, and $\mathrm{y}$ direction, while the other was restrained in y direction only (Figure 2). 


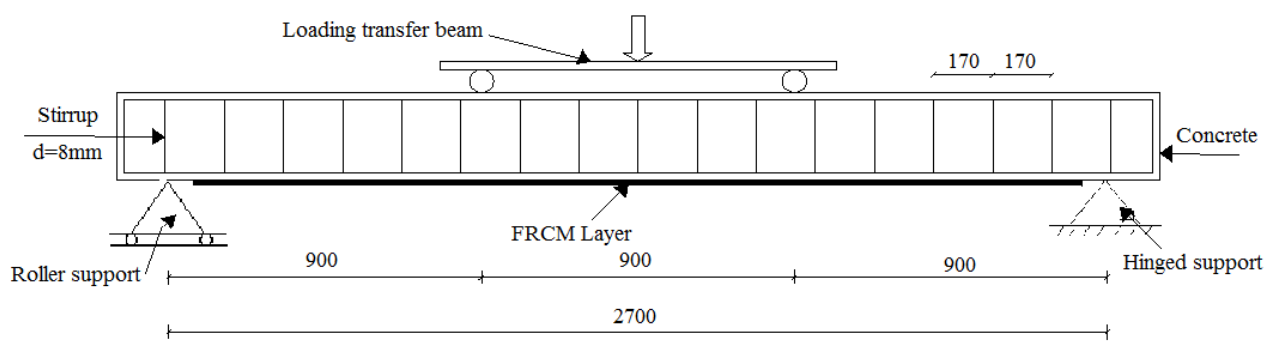

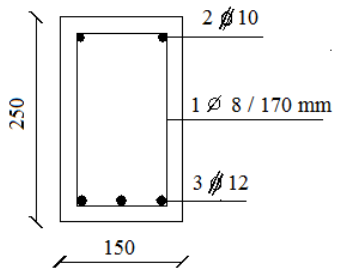

$\mathrm{S} 2(\mathrm{M}=0.9 \%)$

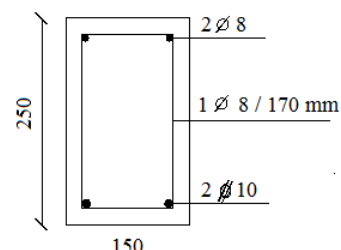

$\stackrel{150}{2}$

$\mathrm{S} 1(\mathrm{M}=0.4 \%)$

Figure (7) - Analyzed investigated beams

Table (4) Properties of the investigated beams [

\begin{tabular}{|l|l|l|l|l|l|}
\hline Beam designation & $\begin{array}{l}A_{\mathrm{s}} \\
(\mathrm{mm})\end{array}$ & $\begin{array}{l}A_{\mathrm{s}}^{\prime} \\
(\mathrm{mm})\end{array}$ & $\begin{array}{l}A_{f} \\
(\mathrm{~mm})\end{array}$ & $\begin{array}{l}\text { Steel } \\
\text { reinforcement } \\
\text { ratio } \mu(\%)\end{array}$ & $\begin{array}{l}\text { Fabric } \\
\text { reinforcement } \\
\text { ratio } \mu_{f}(\%)\end{array}$ \\
\hline $\mathrm{S} 1-\mathrm{N}$ & 157.08 & 100.53 & - & 0.419 & - \\
\hline $\mathrm{S} 1-\mathrm{P} 1-\mathrm{N}$ & 157.08 & 100.53 & 6.75 & 0.419 & 0.018 \\
\hline $\mathrm{S} 1-\mathrm{P} 2-\mathrm{N}$ & 157.08 & 100.53 & 13.5 & 0.419 & 0.036 \\
\hline $\mathrm{S} 1-\mathrm{P} 3-\mathrm{N}$ & 157.08 & 100.53 & 20.25 & 0.419 & 0.054 \\
\hline $\mathrm{S} 2-\mathrm{N}$ & 339.30 & 157.08 & - & 0.905 & - \\
\hline $\mathrm{S} 2-\mathrm{P} 1-\mathrm{N}$ & 339.30 & 157.08 & 6.75 & 0.905 & 0.018 \\
\hline
\end{tabular}

Where: $A_{\mathrm{s}}=$ Area of the tension steel; $A_{\mathrm{s}}^{\prime}=$ Area of compression steel; $A_{f}=$ Area of the fiber mesh sheets; $\mu=$ reinforcement ratio; $\mu_{f}=$ Fabric reinforcement ratio

Table (5) Beam designation in the FEM and its equivalent in the experimental paper [1]

\begin{tabular}{|l|l|l|}
\hline Group & $\begin{array}{l}\text { Beam designation in the } \\
\text { FEM }\end{array}$ & $\begin{array}{l}\text { Equivalent beam designation in experimental paper } \\
{[1]}\end{array}$ \\
\hline \multirow{4}{*}{ S1 } & $\mathrm{S} 1-\mathrm{N}$ & $\mathrm{S} 2-\mathrm{T} 2-0$ \\
\cline { 2 - 3 } & $\mathrm{S} 1-\mathrm{P} 1-\mathrm{N}$ & $\mathrm{S} 2-\mathrm{T} 1-\mathrm{P} 1$ \\
\cline { 2 - 3 } & $\mathrm{S} 1-\mathrm{P} 2-\mathrm{N}$ & $\mathrm{S} 2-\mathrm{T} 1-\mathrm{P} 2-1$ \\
\cline { 2 - 3 } & $\mathrm{S} 1-\mathrm{P} 3-\mathrm{N}$ & $\mathrm{S} 2-\mathrm{T} 1-\mathrm{P} 3-1$ \\
\hline \multirow{3}{*}{$\mathrm{S} 2$} & $\mathrm{~S} 2-\mathrm{N}$ & $\mathrm{S} 1-\mathrm{T} 1-0$ \\
\cline { 2 - 3 } & $\mathrm{S} 2-\mathrm{P} 1-\mathrm{N}$ & $\mathrm{S} 1-\mathrm{T} 1-\mathrm{P} 1-1$ \\
\hline
\end{tabular}


The beams were listed using the following labels: the first letter $\mathrm{S}$ and the first number 1 or 2 indicates the series of the tested beams S1 and S2 the second letter indicates the type of FRCM layers and its number applied to the concrete surface, the letter P refers to the PBO fabric and the letter $\mathrm{N}$ refers to the numerical investigation.

\section{Numerical Results, Validation and Discussion}

To verify the validity of the results obtained from the FEM, a verification of the numerical results with previous experimental results is carried out. In this paper, numerical results obtained from commercial "ABAQUS" were compared with the experimental results from Luciano Ombres, [1]. The obtained numerical results are listed in the Table (6) and compared with the experimental results.

Table (6): FEM and experimental results

\begin{tabular}{|l|l|l|l|l|l|l|}
\hline Beam No. & S1-N & S1-P1-N & S1-P2-N & S1-P3 - N & S2-N & S2-P1-N \\
\hline$P_{\text {exp }}(\mathrm{kN})$ & 39.84 & 45.03 & 50.40 & 52.74 & 74.85 & 80.10 \\
\hline$P_{\text {exp }}(\mathrm{kN})$ & 43.02 & 54.24 & 64.06 & 71.39 & 75.78 & 87.42 \\
\hline$\delta_{y \operatorname{Exp}}(\mathrm{mm})$ & 12.53 & 14.65 & 15.28 & 15.81 & 18.15 & 17.34 \\
\hline$\delta_{u \exp }(\mathrm{mm})$ & 43.78 & 60.44 & 44.62 & 47.46 & 28.50 & 35.50 \\
\hline M.F & CC & CC & IC & IC & CC & CCD \\
\hline$P_{y F E M}(\mathrm{kN})$ & 39.70 & 45.37 & 50.11 & 52.54 & 75.17 & 80.07 \\
\hline$P_{\text {fFEM }}(\mathrm{kN})$ & 41.00 & 58.82 & 65.22 & 77.68 & 78.79 & 88.63 \\
\hline$\delta_{y \text { FEM }}(\mathrm{mm})$ & 13.53 & 14.00 & 15.06 & 14.39 & 16.74 & 17.55 \\
\hline$\delta_{u F E M}(\mathrm{~mm})$ & 42.40 & 61.76 & 44.53 & 46.81 & 30.16 & 33.74 \\
\hline M.F & CC & CC & IC & IC & CC & CCD \\
\hline$\Delta_{1}(\%)$ & 99.65 & 100.76 & 99.42 & 99.62 & 100.43 & 99.96 \\
\hline$\Delta_{2}(\%)$ & 95.30 & 108.44 & 101.81 & 108.81 & 103.97 & 101.38 \\
\hline$\Delta_{3}(\%)$ & 107.98 & 95.56 & 98.56 & 91.02 & 92.23 & 101.21 \\
\hline$\Delta_{4}(\%)$ & 96.85 & 102.18 & 99.80 & 98.63 & 105.82 & 95.04 \\
\hline
\end{tabular}

Note: $\mathrm{P}_{\mathrm{y}}=$ yielding load, $\mathrm{P}_{\mathrm{f}}=$ failure load, $\delta_{\mathrm{y}}=$ Deflection at yielding load; $\delta_{\mathrm{u}}=$ Deflection at failure load, $\mathrm{CC}=$ Concrete crushing, $\mathrm{IC}=$ Intermediate crack debonding and $\mathrm{CCD}=$ Concrete crushing and debonding, $\mathrm{MF}=$ Mode of failure, $\Delta_{l}=$ percentage ratio of $P_{y} F E M / P_{y}$ Exp, $\Delta_{2}=$ percentage ratio of $P_{f F E M} / P_{f \text { Exp }}$, and $\Delta_{3}=$ percentage ratio of $\delta_{y}$ FEM $/ \delta_{y}$ Exp,$\Delta_{4}=$ percentage ratio of $\delta_{u F E M} / \delta_{u E x p}, F E M=$ finite elements and Exp $=$ Experimental

\subsection{Load-Deflection Relationships, cracking, and ultimate load}

Figure (8) and (9) show the relation between the applied load and mid span deflection from the beginning of loading up to failure for the investigated RC beams and the behavior of all beams shows three-stages. The first one is cracking stage where it is the same in all beams. The reason for that is all beams have almost the same concrete cross-section and properties. Whereas the second stage is the elastic stage (pre-yielding stage) which start after concrete cracking till the steel yielding. Because of the propagated cracks 
Mohamed Nagah et al., Nonlinear Finite-Element Analysis for Rc Beams Strengthened......

along the investigated beams, the slope of the line decreases and this refers to stiffness decreasing. Moreover, large slope indicates to a large stiffness of the beam in this stage. Whereas the last stage is the post-yielding stage where the cracks increase and expand, moreover the deflection increase with a small increase in corresponding load. This is because of stiffness's of the beams are decreasing, so the slope of the curves is seen as semi horizontal line. Figure (8) shows the comparison between the numerical and experimental load deflection curves to investigate the effect of the number of FRCM layers. Increasing the number of layers leads to an increase in the ultimate load of the beams, as well as the overall rigidity of these beams. This is due to the addition of FRCM layers work as an extra reinforcement for the investigated beams, so these beams show higher stiffness as shown in Figure from (14) to (17). Whereas Figure (9) shows the comparison between the numerical and experimental load deflection curves to investigate the effect of the reinforcement ratio. Moreover, beams with higher reinforcement show higher loading capacity and higher overall beams stiffness. The higher reinforcement leads to an increasing of rigidity as shown in Figures from (10) to (13). Moreover, the using of FRCM system in the case of low reinforcement ratio leads to increase the ultimate load capacity by $43 \%$ and $12.0 \%$ in the case of high reinforcement ratio as shown in Figure (9). Finally, numerical, and experimental results Luciano Ombres, [1], show an acceptable agreement for both yielding and failure load as well as their corresponding deflection. The comparison between the experimental and numerical results of examined beams is presented in Table (6).

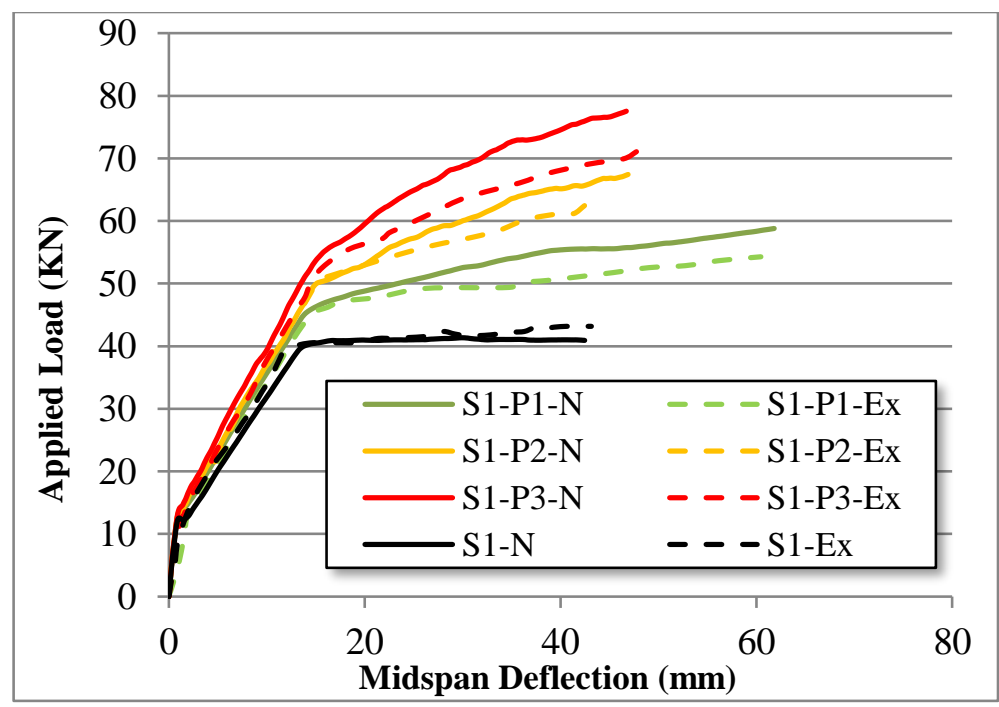

Figure (8) - Load-deflection curves of group (S1) 


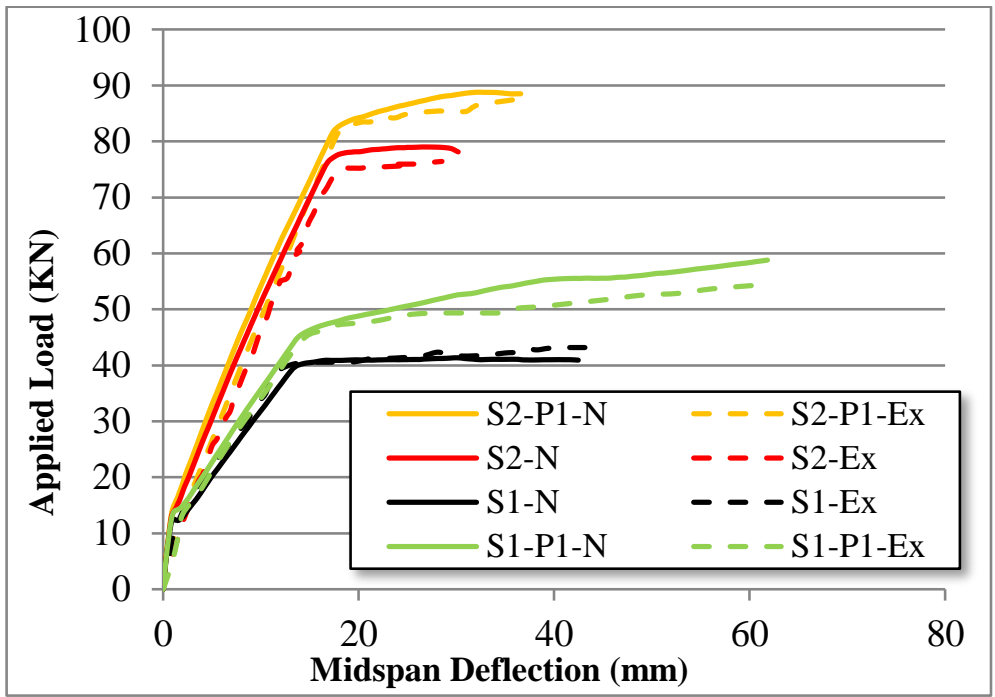

Figure (9) - Load-deflection curves of group (S2)

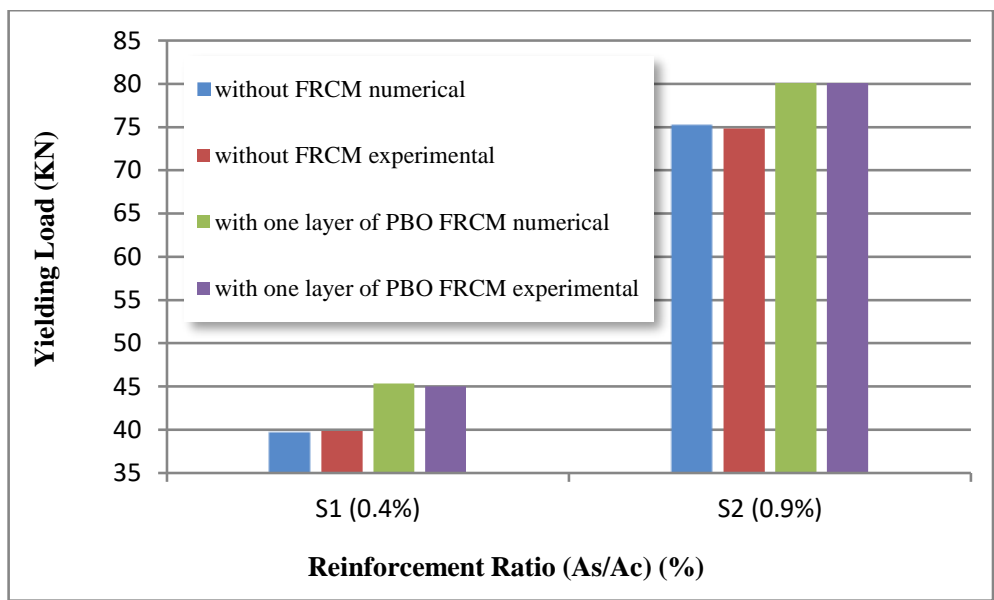

Figure (10) - Reinforcement ratio (As/Ac) (\%) with yielding load (KN) 
Mohamed Nagah et al., Nonlinear Finite-Element Analysis for Rc Beams Strengthened......

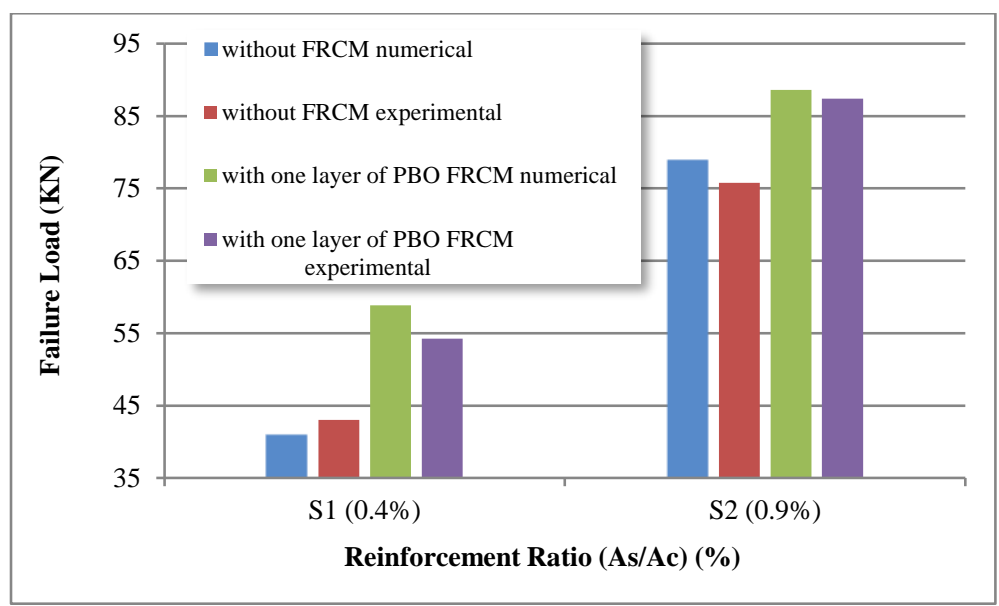

Figure (11) - Reinforcement ratio $(A s / A c)(\%)$ with failure load $(\mathrm{KN})$

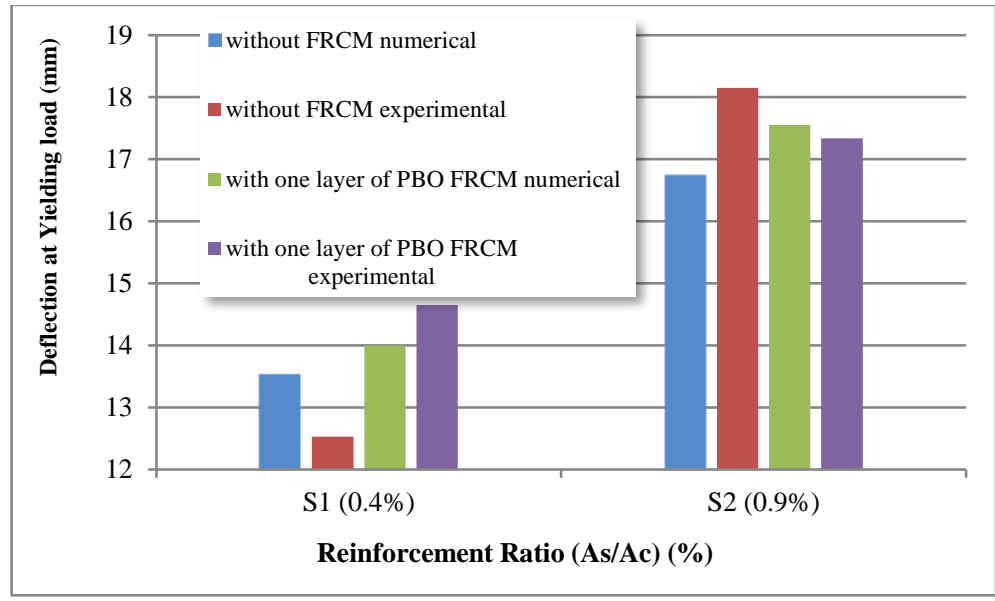

Figure (12) - Reinforcement ratio (As/Ac) (\%) with a deflection at yielding load (mm)

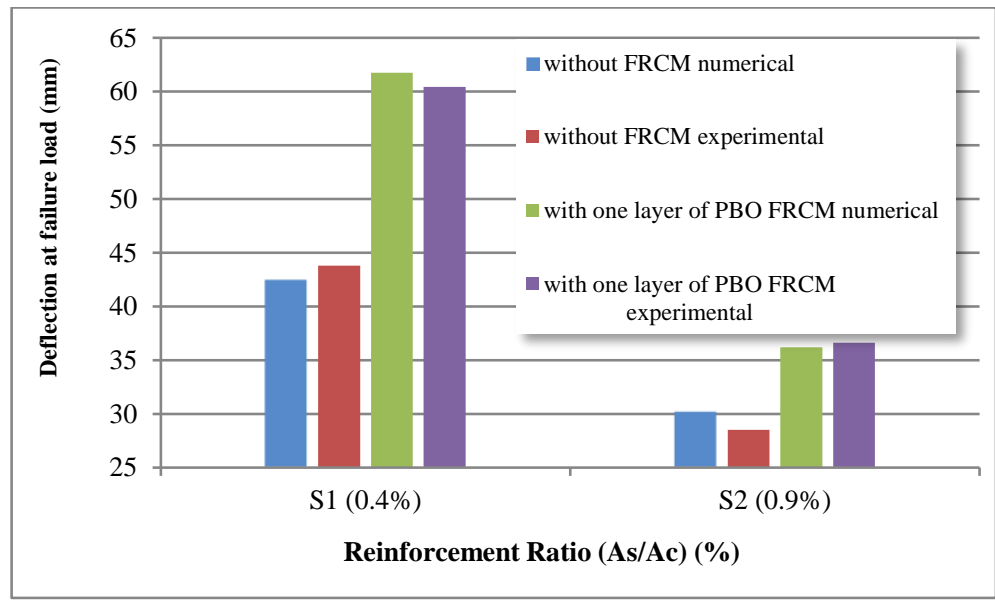

Figure (13) - Reinforcement ratio $(A s / A c)$ (\%) with a deflection at failure load (mm) 


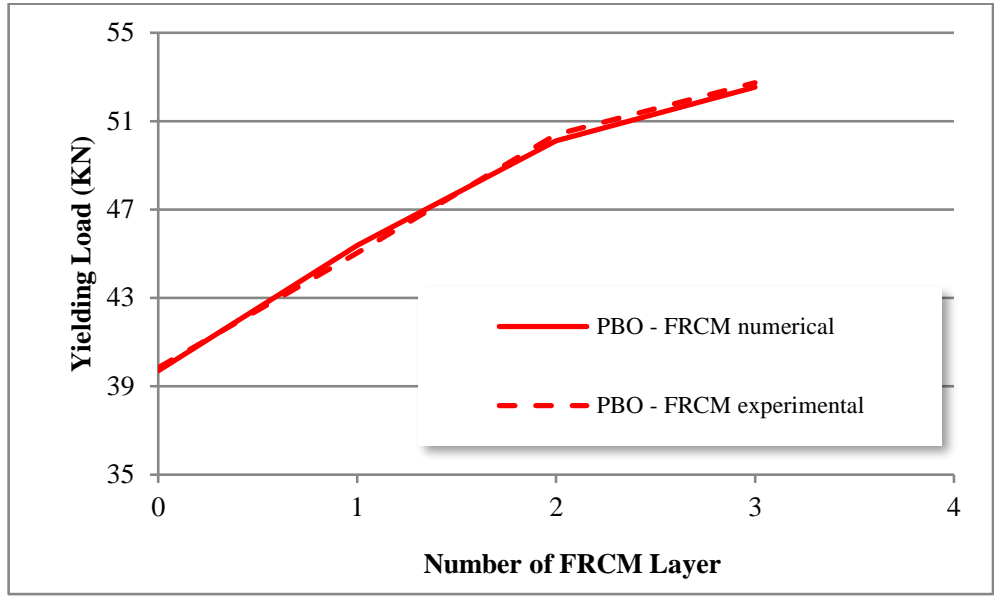

Figure (14) - Number of FRCM layer with yielding load (KN)

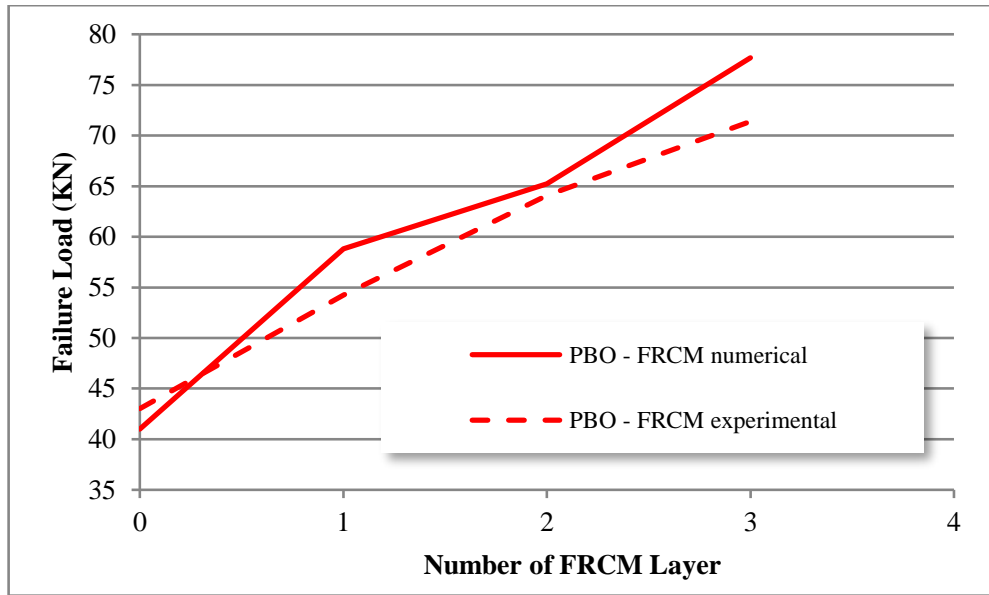

Figure (15) - Number of FRCM layer with failure load (KN)

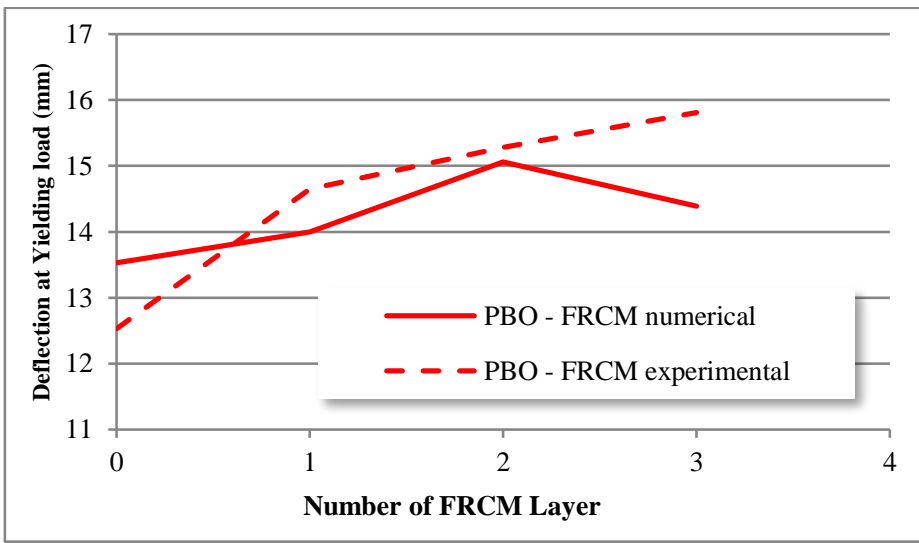

Figure (16) - Number of FRCM layer with a deflection at yielding load (mm) 
Mohamed Nagah et al., Nonlinear Finite-Element Analysis for Rc Beams Strengthened......

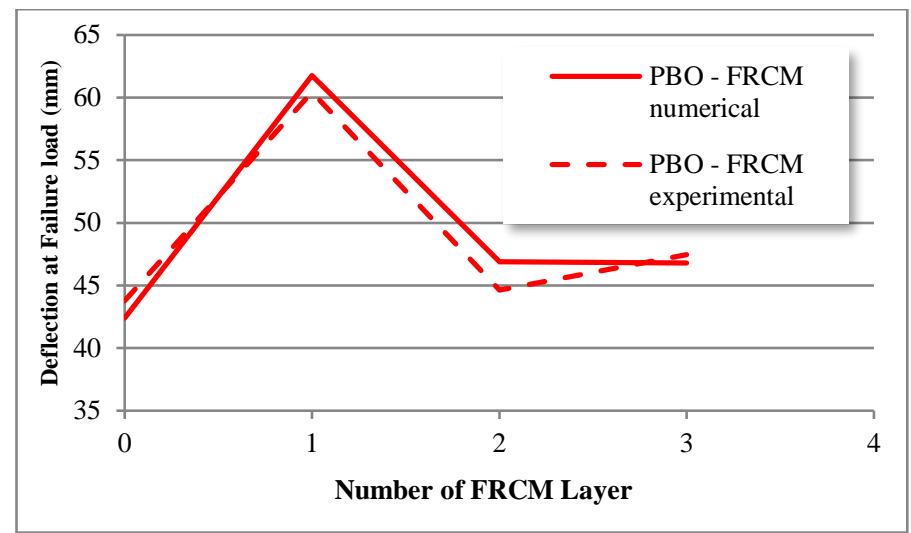

Figure (17) - Number of FRCM layer with a deflection at failure load (mm)

\subsection{Cracking Pattern and Failure Mode}

\subsubsection{Cracks Pattern and Strain Distribution}

Figure (18) shows the numerical versus experimental cracking pattern of (S2$\mathrm{P} 1-\mathrm{N})$ and $(\mathrm{S} 1-\mathrm{P} 2-\mathrm{N})$. The higher strain value indicates the location of wide crack. Moreover, comparing the crack pattern obtained from the FEA with the corresponding experimental result of Luciano Ombres, [1], showed a good agreement. Beams with a lower reinforcement ratio show that higher strain values compared with the beams have a high reinforcement ratio. Increasing of reinforcement ratio leads to reducing the vertical intermediate flexural cracks and increasing the inclined shear cracks. The increasing of reinforcement ratio leads to increasing the stiffness of beams and restricting the cracks opening as shown Figure (19). Moreover, beams with a higher layer's number of FRCM show lower strain values and shrinkage cracking zone. The increasing of the number of FRCM layers leads to restricting the cracks opening and reducing the strain distribution as shown in Figure (20).

\subsubsection{Failure mode}

For the beams without strengthening (S1-N and S2-N) and the beam with one-layer FRCM reinforcement (S1-P1-N), the failure occurred due to the concrete crushing in compression side as shown in Figure (21). The failure of the beams strengthened with two and three-layer of PBO - FRCM (S1-P2-N and S1-P3-N) was due to the debonding between the PBO - FRCM layer and the soffit of concrete beams as shown in Figure (22), and the mode failure of beam (S2-P1-N) was due to debonding of PBO - FRCM layer and crushing concrete at the same time as shown in Figure (23). This achieved a good validation with the experimental failure mode, which is obtained from experimental paper Luciano Ombres, [1]. 

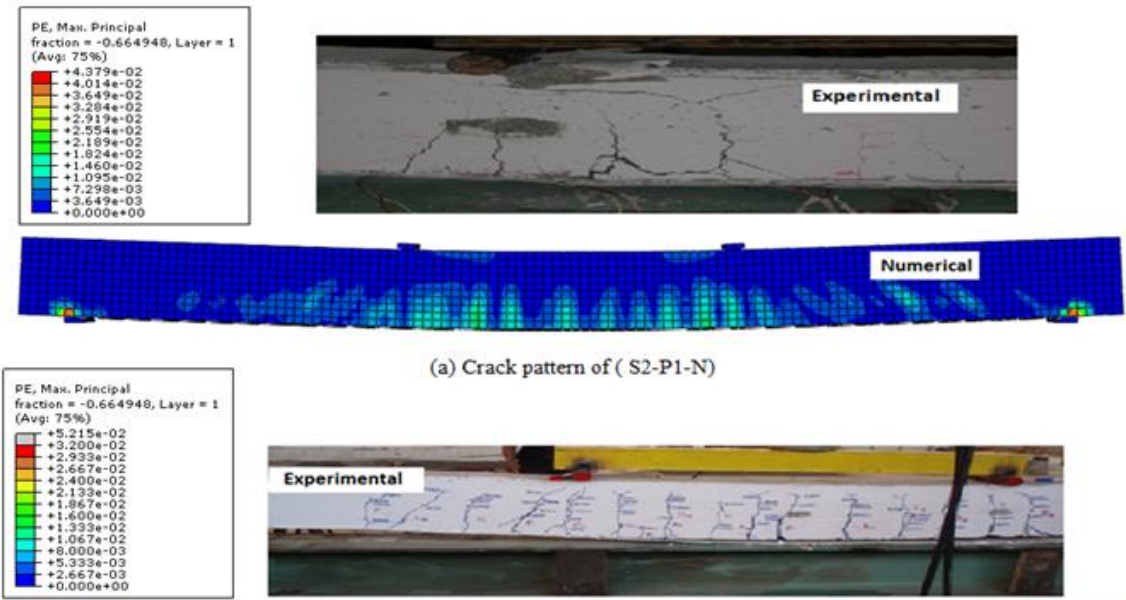

(a) Crack pattern of ( S2-P1-N)
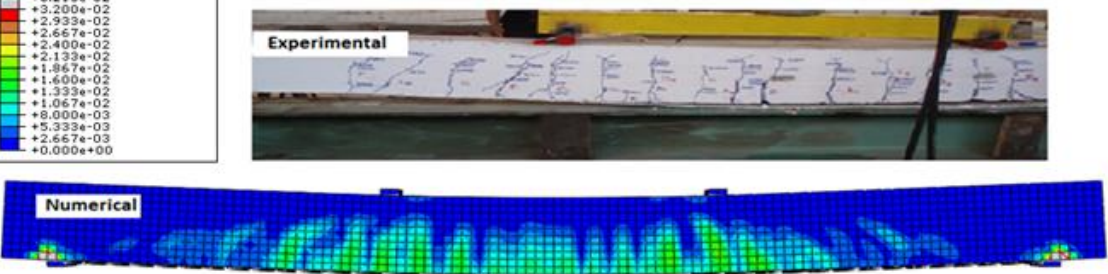

(b) Crack pattern of (S1-P2-N)

Figure (18) - Comparison between numerical and experimental cracking pattern
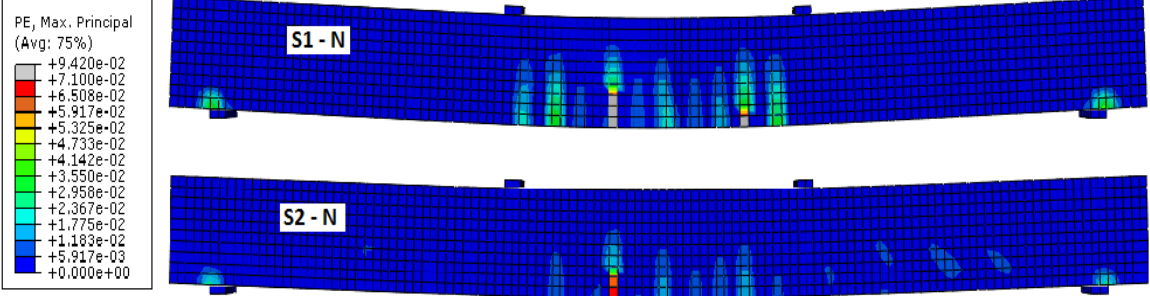

(a) Without FRCM layers

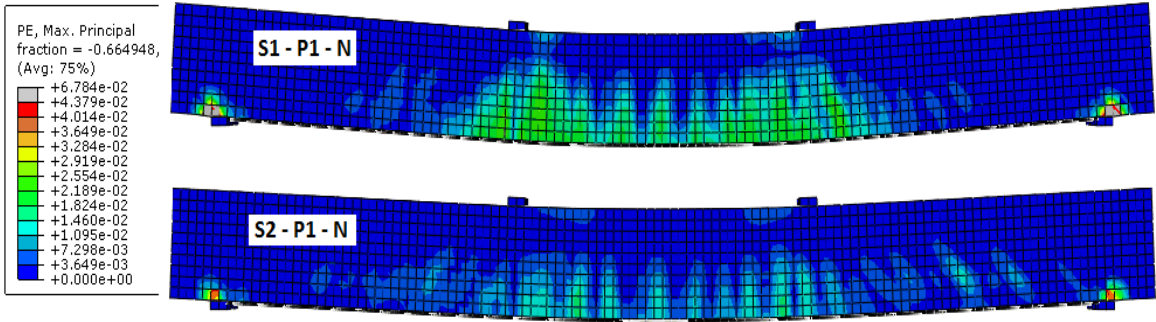

(b) With one layer of FRCM layer

Figure (19) - Effect of reinforcement ratio $(A s / A c)$ on the strain distribution and cracking pattern 


\section{1}

Mohamed Nagah et al., Nonlinear Finite-Element Analysis for Rc Beams Strengthened......
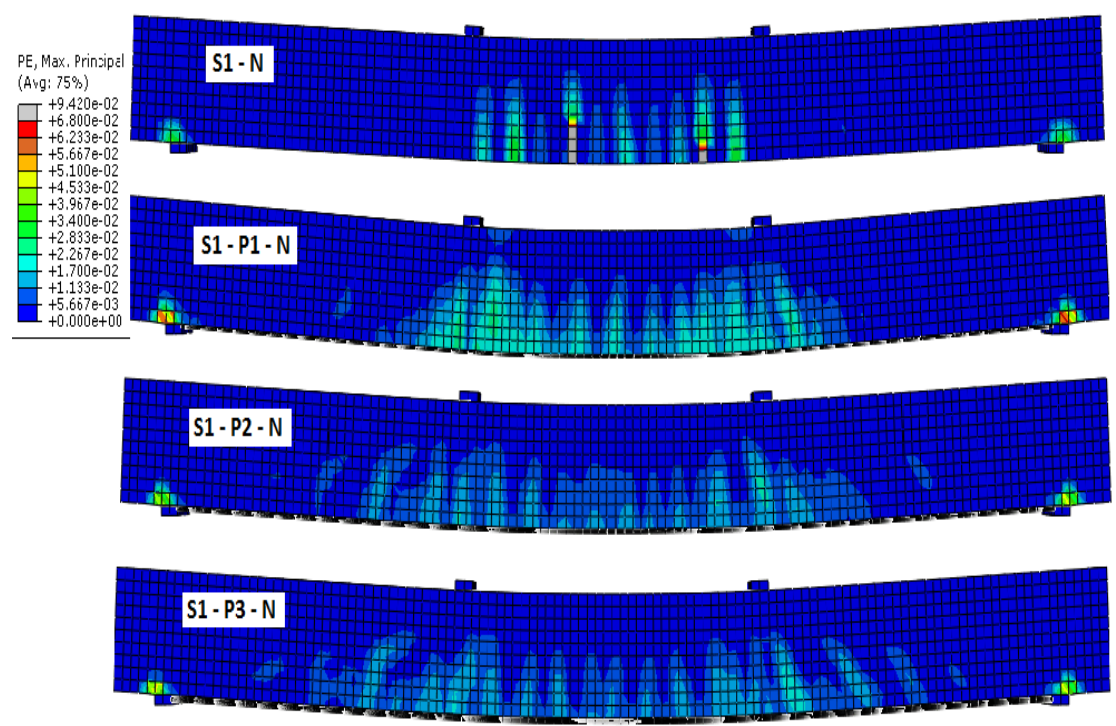

Figure (20) - Effect of number of FRCM layers on the strain distribution and cracking pattern

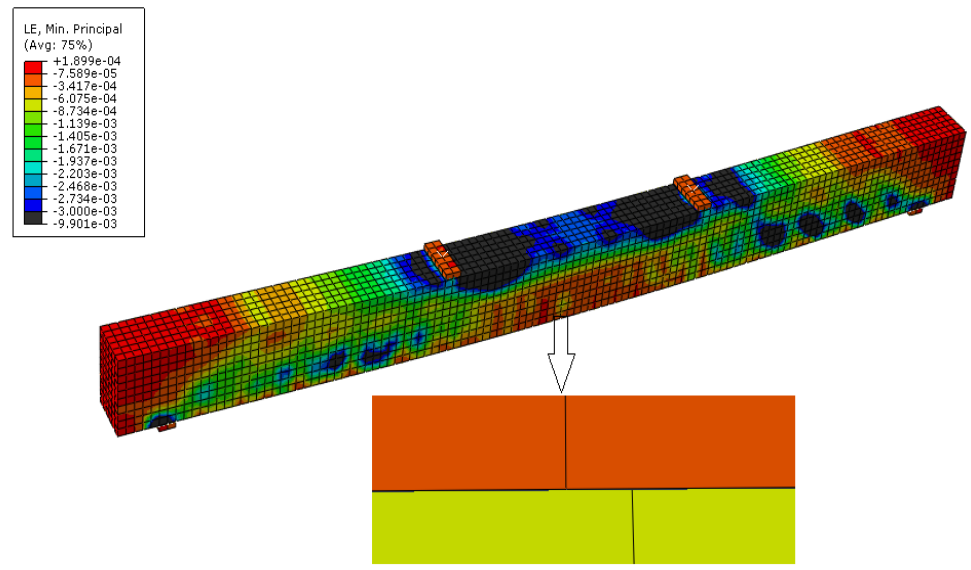

Figure (21) - Type of failure mode (Crushing concrete) 


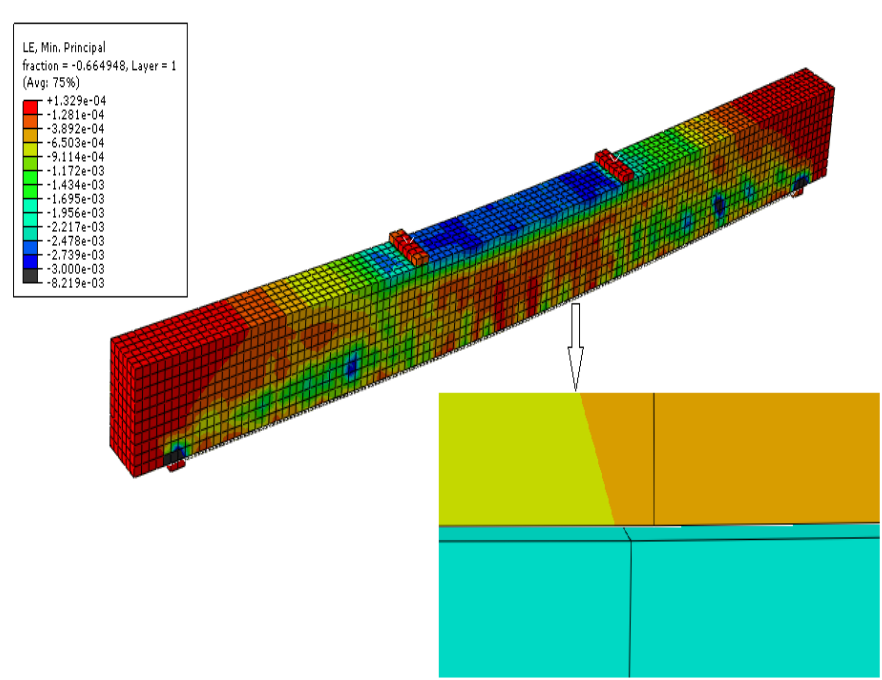

Figure (22) - Type of failure mode (Debonding of PBO - FRCM layer)

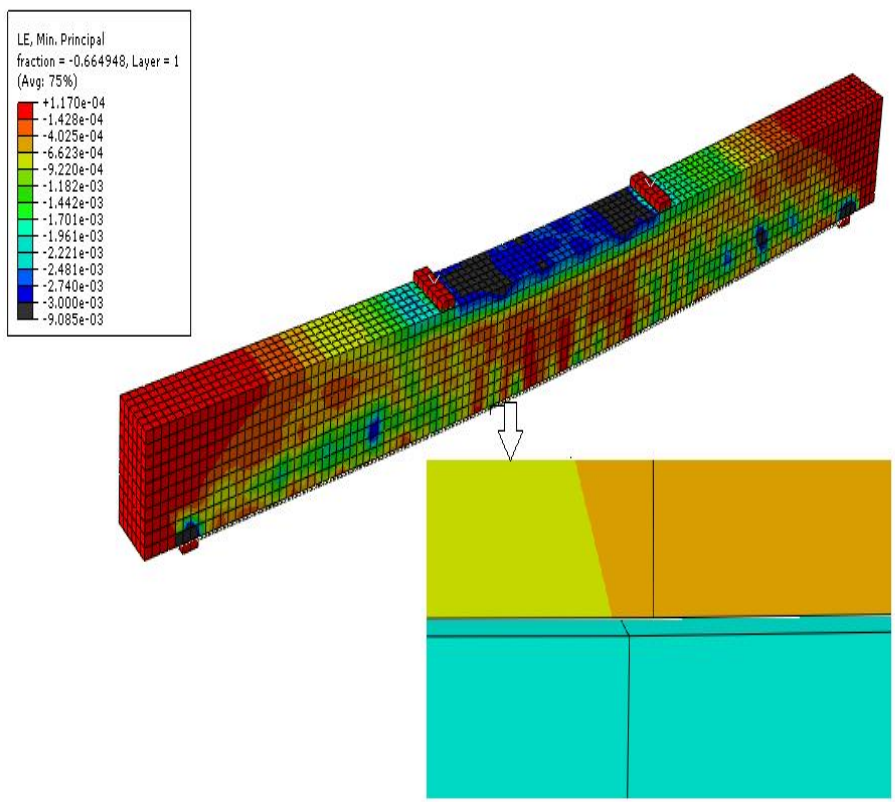

Figure (23) - Type of failure mode (debonding of PBO - FRCM layer and crushing concrete)

\subsection{Strain of FRCM Layer}

Figure (24) shows the load - PBO FRCM strain at mid span of the numerical and experimental results, which discusses the impact of an increase in the number of the layers on the PBO-FRCM strain. Beams with a higher number of layers of FRCM show lower fabric mesh strain values. This because increasing the number of FRCM layers strengthening the beams, making 
Mohamed Nagah et al., Nonlinear Finite-Element Analysis for Rc Beams Strengthened......

them more rigid, reduces the strain distribution and restricts the propagated cracks as shown in Figure (20). Moreover, beams with lower reinforcement ratio show higher PBO-FRCM strain values compared with the beams with high reinforcement ratio. Because increasing reinforcement ratio leads to an increase in the rigidity of beams and make beams stiffer as shown in Figure (25), moreover decreases the propagated cracks as shown in Figure (19). Numerical and experimental results [1] show an acceptable agreement of the load - PBO FRCM strain relationships.

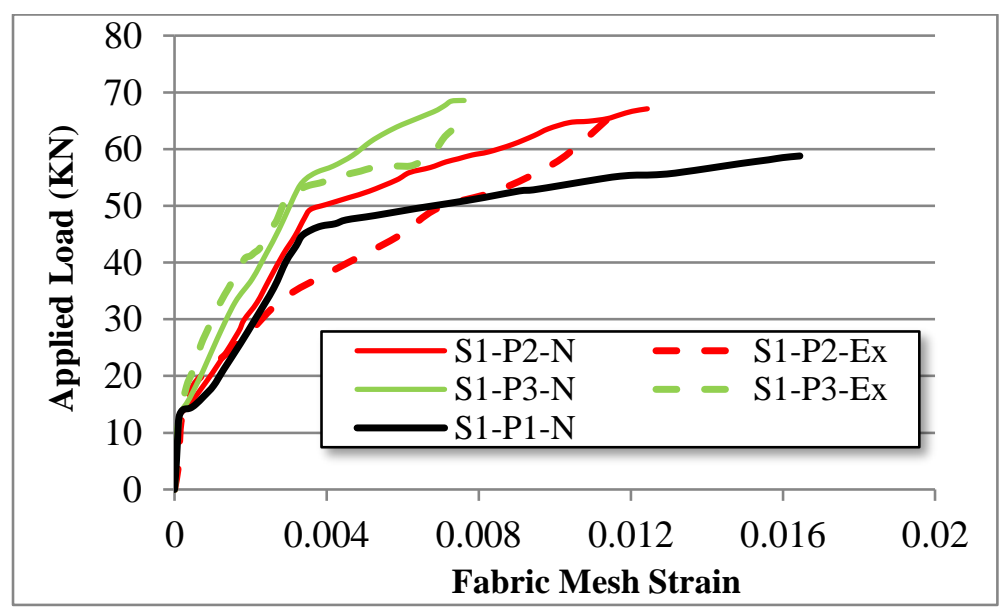

Figure (24) - Load -fabric mesh strain curves of the first group (S1)

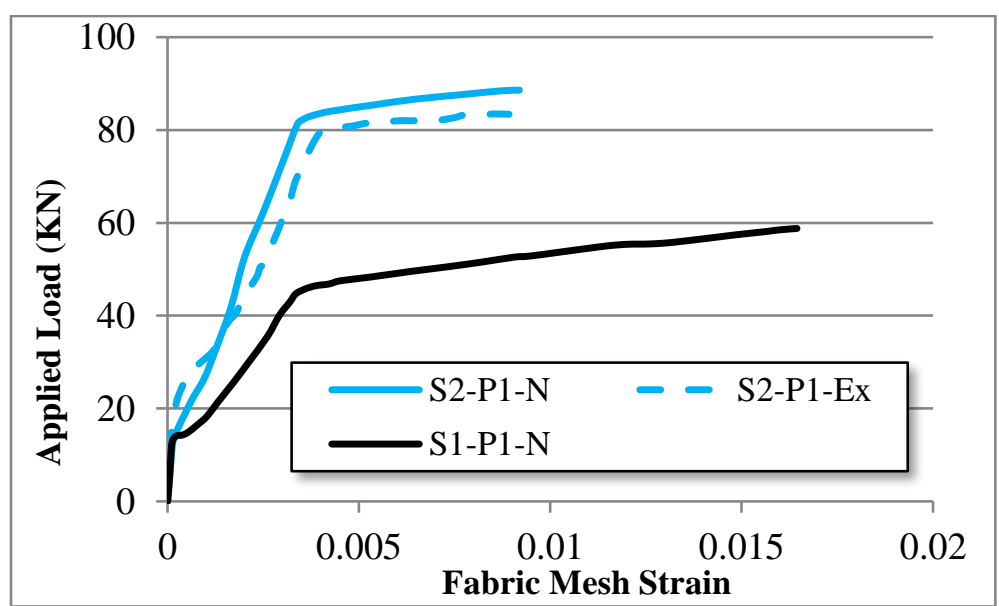

Figure (25) - Load -fabric mesh strain curves of the second group (S2)

\subsection{Concrete Strain}

Figure (26) shows the load versus strain measured at mid-span for all investigated beams. This shows the compressive strain value in concrete of the numerical and experimental results. Investigation of this figure shows a 
good agreement between the numerical and experimental results of Luciano Ombres, [1].

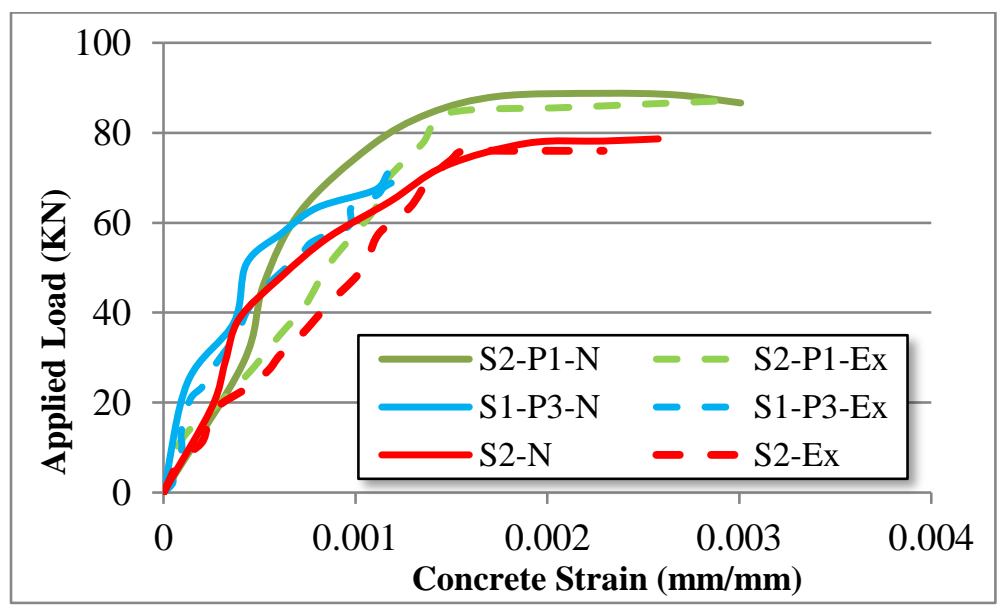

Figure (26) - Comparison of numerical and experimental load - concrete strain curves at mid span

\section{Conclusion}

Finite-element analysis was conducted to simulate RC beams strengthened with fabric-reinforced cementitious matrix. The simulation was verified against the experimental results of Luciano Ombres, [1], for six strengthened large-scale RC beams. Based on the presented analysis, the following conclusions can be reported:

- The FEA adequately predicted the experimental response of the simulated beams in terms of strength, stiffness, and deformation capacity.

- Using of the PBO-FRCM system improves the flexural capacity of strengthened beams. The ultimate capacity and the yielding load of strengthened beams increased from $43 \%$ to $89 \%$ and $14 \%$ to $32 \%$ respectively compared with the un-strengthened beam.

- Increasing either reinforcement ratio or the number of FRCM layers improved the total serviceability of the investigated beams. Increasing reinforcement ratio and number of FRCM layers decreases the strain distribution and restricts the cracks opening.

- Increasing the number of layers was more significant at lower reinforcement ratio.

- Increasing either reinforcement ratio or number of FRCM layers resulted in lower ductility.

\section{References}


[1] Ombres, L. (2011). Flexural analysis of reinforced concrete beams strengthened with a cement based high strength composite material. Composite Structures, 94(1), 143-155.

[2] Jabr, A., et al. (2017). Effect of the fiber type and axial stiffness of FRCM on the flexural strengthening of RC beams. Fibers, 5(1).

[3] Elghazy, M., et al. (2017). Effect of corrosion damage on the flexural performance of RC beams strengthened with FRCM composites. Composite Structures, (180), 994-1006.

[4] Aljazaeri, Z. R., et al. (2019). A novel and effective anchorage system for enhancing the flexural capacity of RC beams strengthened with FRCM composites. Composite Structures, 210, 20-28.

[5] Abaqus. Version 6.14. Dassault Systemes: 3DS Paris Campus; 2014.

[6] Michał, S., \& Andrzej, W. (2015). Calibration of the CDP model parameters in Abaqus. The 2015 Wourld Congress on Advances in Structural Engineering and Mechanics (ASEM15)

[7] Carreira, D. J., \& Chu, K. H. (1985). Stress-strain relationship for plain concrete in compression. Journal Proceedings (Vol. 82, No. 6, pp. 797-804)

[8] Salve, A. K., \& Jalwadi, S. N. (2015). Implementation of cohesive zone in ABAQUS to investigate fracture problems. Proceedings of the National Conference for Engineering Postgraduates RIT, NConPG-15, (pp. 60-66)

[9] Ombres, L. (2012). Debonding analysis of reinforced concrete beams strengthened with fibre reinforced cementitious mortar. Engineering Fracture Mechanics, 81, 94-109.

[10] Ombres, L. (2015). Analysis of the bond between fabric reinforced cementitious mortar (FRCM) strengthening systems and concrete. Composites Part B: Engineering, 69, 418-426.

[11] Younis, A., \& Ebead, U. (2018). Bond characteristics of different FRCM systems. Construction and Building Materials, 175, 610-620.

[12] Toutanji, H., et al. (2006). Flexural behavior of reinforced concrete beams externally strengthened with CFRP sheets bonded with an inorganic matrix. Engineering structures, 28(4), 557-566

[13] Hawileh, R. A., et al. (2015). Temperature effect on the mechanical properties of carbon, glass, and carbon-glass FRP laminates. Construction and Building Materials, 75, 342-348.

[14] Silva, M. A., \& Biscaia, H. (2008). Degradation of bond between FRP and RC beams. Composite structures, 85(2), 164-174. 


\section{التحليل اللاخطي للكمرات الخرسانية المسلحة والمقواه بوسط اسمنتي مسلح بنسيج من الالياف}

نظر الأوجه القصور في نظام التماسك الخارجي الذي يتكون من المواد الايبوكسية

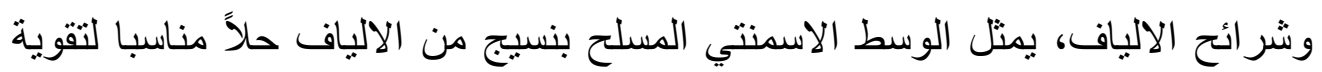

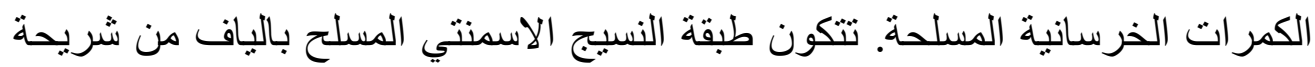

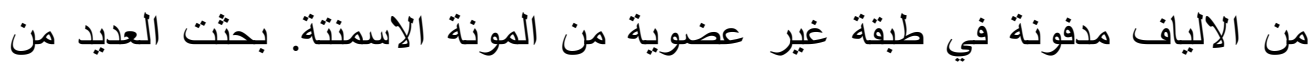
الدر اسات العملية ناثير تقوية الكمر ات الخرسانية المقو اة بنسيج اسمنتي مسلح بالالياف. لذلك الهدف الاساسي من هذه الدراسة هو تقديم دراسة عددية للكمرات الخرساتية التهاتية المسلحة والمقواة بنسيج اسمنتي مسلح بالالياف. وكذلك التاكد من صحة التهة النتائج المتحصل عليها من البرنامج من خلال مقارنتها بالنتائج العملية المسجلة بدر اسة سابقة

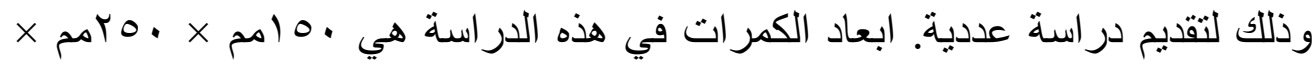

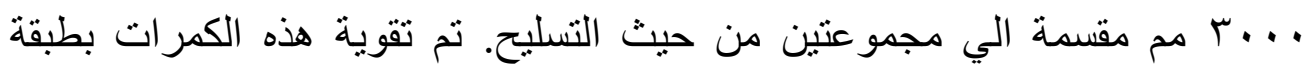

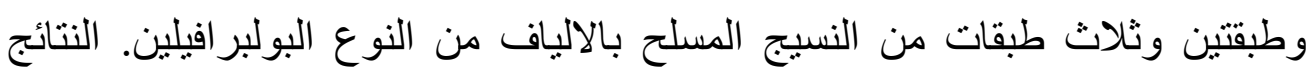

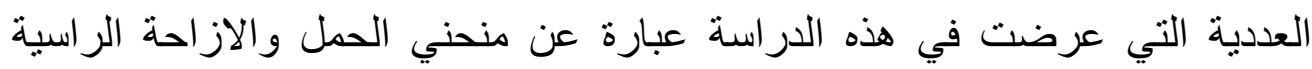

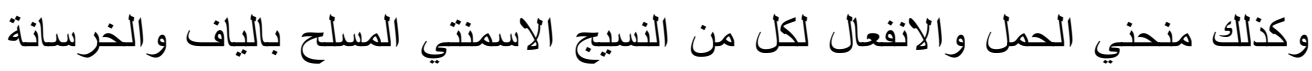

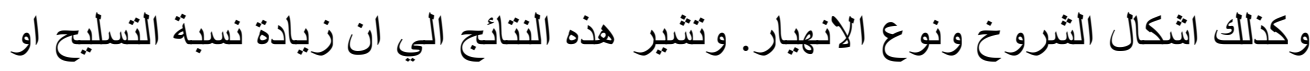

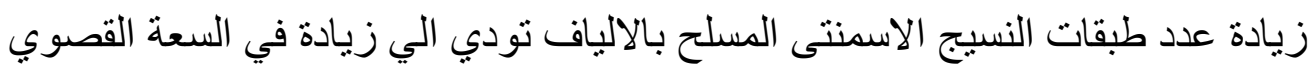

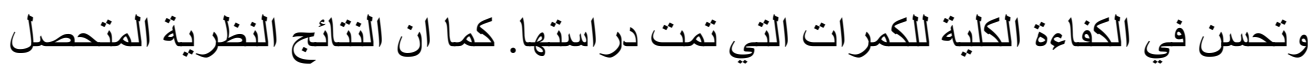

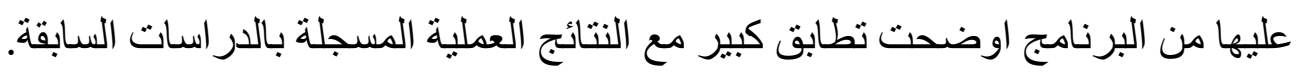

